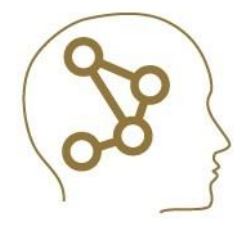

\title{
Computer-Aided Model for the Classification of Acute Inflamations via Radial-Based Function Artificial Neural Network
}

\author{
Mehmet Onur Kaya (D) \\ Firat University, Faculty of Medicine, Department of Biostatistics and Medical Informatics, Elazig, Tturkey. (e-mail: mokaya @ firat.edu.tr).
}

\section{ARTICLE INFO}

Received: Apr.,12.2021

Revised: Apr. 30.2021

Accepted: May.,19.2021

Keywords:

Classification

Radial-based function

Artificial neural network

Acute Inflammation

Corresponding author: Mehmet Onur

Kaya

$\triangle$ mokaya@firat.edu.tr

鲴+904242370000/4672

ISSN: 2548-0650

DOI: https://doi.org/10.52876/jcs.913730

\begin{abstract}
Objective: This study aimed to compare the classification performance of acute inflammation by applying the RBF ANN model on an open-access acute inflammation data set and determining the risk factors that may be associated with acute inflammation markers.

Material and Methods: In the study, Nephritis of renal pelvis origin was classified using the open access "Acute Inflammation" data set RBF ANN model, and risk factors that could be associated were revealed. The success of RBF ANN is presented by different performance metrics.

Results: The success of classifying Nephritis of renal pelvis origin with the RBF ANN model has been demonstrated to be excellent $(A U C=1$, Accuracy $=100 \%)$. In addition, the RBF ANN model revealed that the most important variable among the risk factors that may be associated with Nephritis of renal pelvis origin is "temperature of patient".

Conclusion: As a result, the obtained findings show that the RBF ANN model provides very successful predictions in the classification of Nephritis of renal pelvis origin. Also, it has been shown that the importance values of factors associated with Nephritis of renal pelvis origin are estimated with the RBF classification model and can be used safely in preventive medicine applications.
\end{abstract}

\section{INTRODUCTION}

I NFLAMMATION Occurs due to the cellular and molecular response of the body against biological, chemical, or physical stimuli. In the acute phase of inflammation, immune cells, cytokines, chemokines, and acute-phase proteins migrate to the injury site and initiate the process. In the acute phase of the inflammatory response, cells of the immune system migrate to the injury site in a carefully regulated sequence of events facilitated by soluble mediators such as cytokines, chemokines, and acute-phase proteins. A successful acute inflammatory response results in eliminating infectious agents, which was followed by the thawing and repair phase through macrophages. If the acute inflammatory response cannot eradicate the pathogen, the inflammatory process continues and acquires new properties. Neutrophil infiltrate is replaced by macrophages and, in case of infection, by $\mathrm{T}$ cells. If the combined effect of these cells is still insufficient, a chronic inflammatory condition involving the formation of granulomas and tertiary lymphoid tissues occurs $[1,2]$.

Recently, studies conducted with neutrophil/lymphocyte ratio (NLR), thrombocyte/lymphocyte ratio (PLR), and erythrocyte distribution width (RDW) in peripheral blood and inflammation markers draw attention in the diagnosis and follow-up of inflammation. Hematology and clinical chemistry data obtained from standard laboratory studies may be the first indication of the presence and sometimes the location of the inflammation. Although they are sensitive indicators of inflammation, these markers cannot often identify the disturbing cause. The profile seen in a particular inflammatory condition depends on the severity, chronicity, and mechanisms involved in the inflammatory process and the response and adaptation capacity and type of the individual's immune system $[3,4]$. Although changes in hematology dynamics, acute phase proteins, complementary factors, and cytokines are common for almost all inflammatory conditions and can be measured by various techniques, it has been 
reported that individual factors may be strongly associated with specific pathological events [5].

Artificial Neural Networks (ANNs) are computer systems designed to directly realize the features of learning, which are one of the characteristics of the human brain, such as the ability to derive, generate, and discover new knowledge without assistance [6]. Without any assumptions, ANN can provide nonlinear modeling without any prior knowledge of the input and output variables [7]. Artificial neural networks have proven to be efficient in many applications, including classification, modeling, and prediction $[8,9]$.

Radial-based function (RBF) neural networks are threelayer feedforward networks with an input layer, an output layer, and a single hidden layer. The network's name as a transfer function comes from this hidden layer, which uses radial functions. Although the network's inputs are not linear, the output is [10]. The input layer, which is made up of source nodes, links the network to the outside world. The network's single hidden layer performs a nonlinear transformation from the input to the hidden field. A nonlinear constant transformation with radial-based transfer functions is used to convert the input layer to the hidden layer. The output layer is a linear layer that responds to the network, represented by the transfer signal applied to the input layer. An adaptive and linear transformation is implemented from the secret layer to the output layer [11].

This study aimed to compare the classification performance of acute inflammation by applying the RBF ANN model on an open-access acute inflammation data set and determining the risk factors that may be associated with acute inflammation markers.

\section{MATERIAL AND METHODS}

\subsection{Dataset}

The data set "Acute Inflammations" was obtained from the database https://archive.ics.uci.edu/ml/datasets/Acute+Inflammations to analyze the performance of the RBF ANN model and to assess risk factors in this study [12]. The names, types, and properties of the data set variables are presented in Table 1.

TABLE 1

PROPERTIES OF THE VARIABLES IN THE STUDY

\begin{tabular}{|c|c|c|c|}
\hline Variable & Variable Description & Variable Type & Variable Role \\
\hline V1 & Temperature of patient $\left(35^{\circ} \mathrm{C}-42^{\circ} \mathrm{C}\right)$ & Quantitative & Input \\
\hline $\mathbf{V 2}$ & Occurrence of nausea ( $0:$ No, $1:$ Yes) & Qualitative & Input \\
\hline $\mathbf{V 3}$ & Lumbar pain (0: No, 1:Yes) & Qualitative & Input \\
\hline V4 & Urine pushing (0: No, 1:Yes) & Qualitative & Input \\
\hline V5 & Micturition pains (0: No, 1:Yes) & Qualitative & Input \\
\hline V6 & $\begin{array}{l}\text { Burning of urethra, itch, swelling of } \\
\text { urethra outlet } \\
(0: \text { No, 1:Yes })\end{array}$ & Qualitative & Input \\
\hline V7 & $\begin{array}{l}\text { Inflammation of urinary bladder } \\
(0: \text { No, } 1 \text { :Yes })\end{array}$ & Qualitative & Input \\
\hline V8 & $\begin{array}{l}\text { Nephritis of renal pelvis origin }(0: \text { No, } \\
1 \text { :Yes) }\end{array}$ & Qualitative & Output \\
\hline
\end{tabular}

\subsection{Radial-Based Function Artificial Neural Networks}

The Radial Based Function Artificial Neural Network (RBF ANN) was created in 1988 and joined the history of ANN by adding it to the filtering problem. It was inspired by the impact reaction behaviors found in biological nerve cells. The teaching of RBF ANN models can be seen as a multidimensional curve-fitting approach. As a result, the RBF ANN model's training efficiency becomes an interpolation challenge, requiring the model to find the most suitable surface for the data in the output vector space. The input layer, hidden layer, and output layer of RBF ANN models are represented in three layers, similar to the general ANN architecture. RBF ANNs, on the other hand, use radial-based activation functions and nonlinear cluster analysis in the transformation from the input layer to the hidden layer, unlike traditional ANN structures $[13,14]$. As with other ANN forms [15], the arrangement between the hidden and output layers continues to work.

In the construction of the RBF ANN model, about $63 \%$ and $37 \%$ of the complete dataset were utilized for training and testing steps, respectively. The rescaling technique for the input variables was standardized for the related model. The number of units in the hidden layer was 10 , the hidden layer activation function was Softmax, the number of units in the output layer was 2, and the output layer activation function was Identity, and the error function was Sum of Squares.
Hyperparameters of the models were optimized by the scaled conjugate gradient method.

\subsection{Performance Evaluation of the RBF ANN Model}

Performance metrics [16] such as Accuracy, Sensitivity, Specificity, Positive predictive value (PPV), Negative predictive value (NPV), F-score, and Area under the curve (AUC) were used in the performance evaluation of the RBF ANN model to predict factors that may be associated with acute nephritis.

\subsection{Data Analysis}

IBM SPSS statistics 26.0 program was used for all analyzes in the study. The compliance of continuous variables to the normal distribution was evaluated using the Shapiro Wilk test. The comparison of continuous variables that do not provide the assumption of normal distribution between two independent groups (Decision outcome: Yes and No) was performed with the Mann Whitney $U$ test, and descriptive statistics were presented as median (min-max). In the analysis of categorical variables, Pearson chi-square test was used and descriptive statistics were presented as frequency (\%). The significance level was accepted as 0.05 . 


\section{RESULTS}

Table 2 shows the statistical analysis results for the variables in the data set. Statistically, important $\mathrm{p}$ values are bolded in the table. As can be seen from the table, statistically significant differences were found for other variables, except for the "Micturition pains" variable.

TABLE 2

STATISTICAL COMPARISONS OF VARIABLES ACCORDING TO DECISION: NEPHRITIS

\begin{tabular}{|c|c|c|c|c|}
\hline \multirow{2}{*}{\multicolumn{2}{|c|}{ Variables }} & \multicolumn{2}{|c|}{ Nephritis of renal pelvis origin } & \multirow{2}{*}{ p-value } \\
\hline & & No $(n=70)$ & Yes $(n=50)$ & \\
\hline $\begin{array}{l}\text { Temperature of patient } \\
\text { [Median (Min-Max)] }\end{array}$ & & $37.30(35.50-41.50)$ & $\begin{array}{c}40.55(38.00 \\
-41.50)\end{array}$ & $<0.001$ \\
\hline \multirow{2}{*}{ Occurrence of nausea $\mathrm{n}(\%)$} & No & $70(100.00 \%)$ & $21(42.00 \%)$ & \multirow{2}{*}{$<0.001$} \\
\hline & Yes & $0(00.00 \%)$ & $29(58.00 \%)$ & \\
\hline \multirow{2}{*}{ Lumbar pain $\mathrm{n}(\%)$} & No & $50(71.40 \%)$ & $0(00.00 \%)$ & \multirow{2}{*}{$<0.001$} \\
\hline & Yes & $20(28.60 \%)$ & $50(100.00 \%)$ & \\
\hline \multirow{2}{*}{ Urine pushing $\mathrm{n}(\%)$} & No & $30(42.90 \%)$ & $10(20.00 \%)$ & \multirow{2}{*}{0.009} \\
\hline & Yes & $40(57.10 \%)$ & $40(80.00 \%)$ & \\
\hline \multirow{2}{*}{ Micturition pains $\mathrm{n}(\%)$} & No & $40(57.10 \%)$ & $21(42.00 \%)$ & \multirow{2}{*}{0.102} \\
\hline & Yes & $30(42.90 \%)$ & $29(58.00 \%)$ & \\
\hline \multirow{2}{*}{$\begin{array}{c}\text { Inflammation of urinary } \\
\text { bladder } \mathrm{n}(\%)\end{array}$} & No & $30(42.90 \%)$ & $31(62.00 \%)$ & \multirow{2}{*}{0.039} \\
\hline & Yes & $40(57.10 \%)$ & $19(38.00 \%)$ & \\
\hline \multirow{2}{*}{$\begin{array}{c}\text { Burning of urethra, itch, } \\
\text { swelling of urethra outlet } n(\%)\end{array}$} & No & $50(71.40 \%)$ & $20(40.00 \%)$ & \multirow{2}{*}{0.001} \\
\hline & Yes & $20(28.60 \%)$ & $30(60.00 \%)$ & \\
\hline
\end{tabular}

Classification matrices of training and testing steps for the RBF ANN model are given in Table 3.

TABLE 3

Classification Matrices of TRAining AND Testing Steps

\begin{tabular}{|c|c|c|c|c|}
\hline \multicolumn{5}{|c|}{ Training Step } \\
\hline & & \multicolumn{2}{|c|}{ Reference } & \multirow{2}{*}{ Total } \\
\hline & & No & Yes & \\
\hline \multirow{3}{*}{ } & No & 46 & 0 & 46 \\
\hline & Yes & 0 & 30 & 30 \\
\hline & Total & 46 & 30 & $76(63.3 \%)$ \\
\hline \multicolumn{5}{|c|}{ Testing Step } \\
\hline & & \multicolumn{2}{|c|}{ Reference } & \multirow{2}{*}{ Total } \\
\hline & & No & Yes & \\
\hline \multirow{3}{*}{ } & No & 24 & 0 & 24 \\
\hline & Yes & 0 & 20 & 20 \\
\hline & Total & 24 & 20 & $44(36.7 \%)$ \\
\hline
\end{tabular}

The values of the performance metrics obtained from the RBF ANN model to classify acute nephritis in the test step are given in Table 4.

TABLE 4

ACUTE NEPHRITIS ClAsSIFICATION PERFORMANCE METRICS OF THE RBF ANN MODEL

\begin{tabular}{lc}
\hline Performance Metrics & Value \\
\hline Accuracy (\%) & 100 \\
\hline Sensitivity (\%) & 100 \\
\hline Specificity (\%) & 100 \\
\hline PPV (\%) & 100 \\
\hline NPV (\%) & 100 \\
\hline F1-score (\%) & 100 \\
\hline AUC & 1 \\
\hline
\end{tabular}

The importance values of the input variables in the data set obtained from the RBF ANN model are presented in Table 5 and Figure 1, respectively.
TABLE 5

THE IMPORTANCE VALUES OF THE INPUT VARIABLES

\begin{tabular}{lc} 
Independent Variables & Importance \\
\hline Occurrence of nausea & 0,0100 \\
\hline Lumbar pain & 0,1210 \\
\hline Urine pushing & 0,0990 \\
\hline Micturition pains & 0,0000 \\
\hline Burning of urethra, itch, swelling of urethra outlet & 0,0990 \\
\hline Inflammation of urinary bladder & 0,0870 \\
\hline Temperature of patient & 0,5830 \\
\hline
\end{tabular}

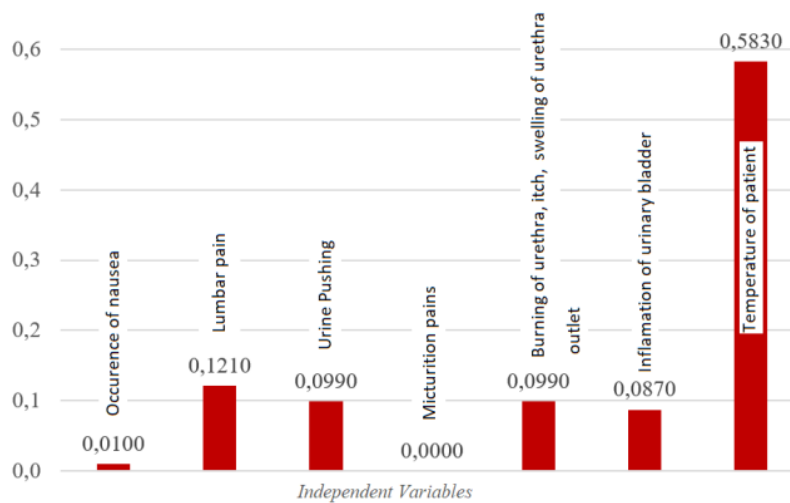

Figure 1. The importance values of possible risk factors associated with nephritis of renal pelvis origin.

\section{CONCLUSION}

Today, science and technology, which are developing in a very dizzying way and growing at an incredible rate, provide us with great products that make our daily life much easier. One of the advanced science and technology products that we can encounter in almost every field in our lives is artificial intelligence. Artificial intelligence, or in other words, artificial neural networks, as in many areas, provide us with valuable contributions by working very quickly and successfully in very sensitive and difficult situations, especially in the field of medicine. It stands out as a very successful clinical decision support system in clinical diagnosis and diagnosis.

Artificial neural networks generally consist of a two-stage process, training and testing. First of all, training is carried out with most of the data set, and it is ensured that the artificial 
neural network learns the problem and solution. In the next step, a test set is given to the learning artificial neural network to determine the solution to the problem. The findings of the artificial neural network are presented with some performance parameters and it can be shown that the relevant network is now ready to solve the desired problem.

This study aimed to classify open-access acute inflammation data of a radial-based functional artificial neural network and reveal the related factors. The performance of the created model has been evaluated using different criteria. Besides, the importance levels of the factors (independent variables) that can be associated with the Nephritis of renal pelvis origin (Dependent variable) for use in preventive medicine practices were also obtained from these models.

According to the results of the performance criteria (accuracy, AUC, sensitivity, negative predictive value, and F score) obtained from the study, it was seen that the RBF ANN made a perfect classification and gave a complete success. While the most important risk factor that may be associated with nephritis of renal pelvis origin is the temperature of the patient, it was observed that micturition pains were the least important.

As a result, the obtained findings show that the RBF ANN model provides very successful predictions in the classification of Nephritis of renal pelvis origin. In addition, it has been shown that the importance values of factors associated with Nephritis of renal pelvis origin are estimated with the RBF classification model and can be used safely in preventive medicine applications.

\section{REFERENCES}

[1] Medzhitov, R. (2008). Origin and physiological roles of inflammation. Nature, 454(7203), 428-435.

[2] Germolec, D. R., Shipkowski, K. A., Frawley, R. P., \& Evans, E. (2018). Markers of inflammation. Immunotoxicity Testing, 57-79.

[3] Chaplin, D. D. (2010). Overview of the immune response. Journal of Allergy and Clinical Immunology, 125(2), S3-S23.

[4] Gaba, C., \& Kushner, I. (1999). Acute-phase proteins and other systemic responses to inflammation. N Engl J Med, 340(6), 448-454.

[5] Sonnenberg, G. F., \& Artis, D. (2015). Innate lymphoid cells in the initiation, regulation and resolution of inflammation. Nature medicine, 21(7), 698-708.

[6] Öztemel, E. (2003). Yapay sinir ağlari. PapatyaYayincilik, Istanbul.

[7] Haykin, S. (1999). Neural Networks, a comprehensive foundation, Prentice-Hall Inc. Upper Saddle River, New Jersey, 7458, 161-175.

[8] Güldoğan, E., Zeynep, T. U. N. Ç., Ayça, A. C. E. T., \& Çolak, C. Performance Evaluation of Different Artificial Neural Network Models in the Classification of Type 2 Diabetes Mellitus. The Journal of Cognitive Systems, 5(1), 23-32.

[9] Vt, S. E., \& Shin, Y. C. (1994). Radial basis function neural network for approximation and estimation of nonlinear stochastic dynamic systems. IEEE transactions on neural networks, 5(4), 594-603.

[10] Kilic, E., Ozbalci, U., \& Ozcalik, H. R. (2012). Lineer Olmayan Dinamik Sistemlerin Yapay Sinir Ağları ile Modellenmesinde MLP ve RBF Yapılarının Karşılaştırılması. ELECO2012 Elektrik-Elektronik ve Bilgisayar Mühendisliği Sempozyomu,(29.11. 2012-01.12. 2012).

[11] Haykin, S. O. (2009). Neural Networks and Learning Machines 3rd Ed. NY: NYL Pearson Prentice Hall.

[12] Czerniak, J., \& Zarzycki, H. (2003). Application of rough sets in the presumptive diagnosis of urinary system diseases. In Artificial intelligence and security in computing systems (pp. 41-51). Springer, Boston, MA.

[13] Hwang, Y. S., \& Bang, S. Y. (1997). An efficient method to construct a radial basis function neural network classifier. Neural networks, 10(8), 1495-1503.

[14] Wu, T. F., \& Yu, T. H. (1998). Unified approach to developing singlestage power converters. IEEE Transactions on Aerospace and Electronic Systems, 34(1), 211-223.

[15] Kaynar, O., Görmez, Y., Iș1k, Y. E., \& Demirkoparan, F. (2016) Değişik Kümeleme Algoritmalarıyla Eğitilmiş Radyal Tabanlı Yapay Sinir Ağlarıyla Saldırı Tespiti. In International Artificial Intelligence and Data Processing Symposium (IDAP'16).

[16] Güldoğan, E., Zeynep, T. U. N. Ç., Ayça, A. C. E. T., \& Çolak, C.
Performance Evaluation of Different Artificial Neural Network Models in the Classification of Type 2 Diabetes Mellitus. The Journal of Cognitive Systems, 5(1), 23-32.

\section{BIOGRAPHIES}

Mehmet Onur Kaya received his BSc from Frrat University in 2009. He received his MSc degree from Frrat University Applied Statistics in 2011 and his PhD degree from Bursa Uludağ University Biostatistics Department in 2016. His research interests are clinical biostatistics, meta-analysis, data mining, expert systems, artificial intelligence, bioinformatics and statistical shape analysis. He joined the Frrat University Biostatistics and Medical Informatics Department as an Assistant Professor in 2017 and is still a faculty member. He is engaged in teaching and research activities in artificial intelligence, data mining, statistical shape analysis and meta-analysis. 